\title{
O Ensino Médio Integrado sob Diferentes Perspectivas para o Ensino de Matemática ${ }^{1}$
}

\author{
Integrated High School under Different Perspectives for Teaching Mathematics
}

\author{
Elion Souza da Silva ${ }^{2}$ \\ Ana Teresa de C. C. de Oliveira ${ }^{3}$
}

\begin{abstract}
Resumo
Neste artigo busca-se apresentar, discutir e articular três perspectivas acerca do Ensino Médio Integrado (EMI): (i) dos documentos oficiais do Ministério da Educação (MEC), (ii) de pesquisadores e educadores que participaram da gênese do EMI ou que se dedicam a pesquisar sobre o tema; e (iii) de professores de matemática do EMI. Esta investigação visa contribuir para a reflexão sobre a concepção do professor de matemática acerca do Ensino Médio Integrado e os desdobramentos, com vistas à formação docente para atuar nesta modalidade. $\mathrm{O}$ texto é um recorte da pesquisa de doutorado que envolve os dois autores: a segunda como orientadora e o primeiro como doutorando, no PEMAT/UFRJ ${ }^{4}$. O fio condutor desta análise foi a articulação entre as três perspectivas, buscando uma compreensão que distinguisse o EMI teorizado (nos documentos oficiais e nos textos de referência sobre o tema), do EMI que é concebido e praticado pelos professores de matemática. Os resultados mostram mais divergências do que convergências entre esses dois paradigmas, evidenciando a necessidade de avaliar e (re)dimensionar alguns aspectos práticos do EMI, especialmente no tocante à formação do professor.
\end{abstract}

Palavras-chave: Ensino Médio Integrado; Educação profissional e tecnológica; Ensino de matemática; Formação de professores de matemática.

\section{Abstract}

In this article we seek to present, discuss and articulate three perspectives on Integrated High School (IHS): (i) official documents of the Ministry of Education (MEC), (ii) researchers and educators who participated in the genesis of IHS or who research on the subject and (iii) mathematics teachers of IHS. This investigation aims to contribute to the reflection on the conception of the mathematics teacher about the Integrated High School and the developments with a view to the teacher education to act in this modality. The text is a clipping of the doctoral research that involves the two authors, the second one as advisor, and the first one as doctoral student, in PEMAT/UFRJ. The conducting wire of our analysis was the articulation between the three perspectives, seeking an understanding that distinguished the IHS theorized (in the official documents and the reference texts

\section{Submetido em: 19/04/2017 - Aceito em: 04/04/2018 - Publicado em: 13/06/2018}

${ }^{1}$ Esta pesquisa conta com o apoio financeiro da Fundação Cearense de Apoio ao Desenvolvimento Científico e Tecnológico (FUNCAP).

${ }^{2}$ Doutorando em Ensino e História da Matemática e da Física pelo PEMAT/UFRJ. Bolsista de Doutorado da FUNCAP. Docente do Instituto Federal de Educação Ciência e Tecnologia do Ceará (IFCE), Iguatu, CE, Brasil. Endereço para correspondência: Rua Maria Dolores Bandeira, 265, Jardim Oásis, CEP: 63507-450, Iguatu, CE, Brasil. E-mail: profelion@gmail.com.

${ }^{3}$ Docente da Faculdade de Educação da Universidade Federal do Rio de Janeiro (FE/UFRJ), Rio de Janeiro, RJ, Brasil. Endereço para correspondência: Rua das Laranjeiras, 144, apt. 301, Laranjeiras, CEP: 22240-000, Rio de Janeiro, RJ, Brasil. E-mail: anateresa@fe.ufrj.br.

${ }^{4}$ Programa de Pós-Graduação em Ensino de Matemática (PEMAT) da Universidade Federal do Rio de Janeiro (UFRJ), Rio de Janeiro, RJ, Brasil. Homepage: www.pg.im.ufrj.br/pemat. 
on the subject), of the IHS which is designed and practiced by mathematics teachers. The results show that there are more divergences than convergences between these two paradigms, evidencing the need to evaluate and (re)dimensionate some practical aspects of IHS, especially with regard to teacher education.

Keywords: Integrated High School; Professional and technological Education; Mathematics teaching; Mathematics teacher Education

\section{Introdução}

O Ensino Médio Integrado (EMI) é uma modalidade de ensino oficialmente presente em várias instituições de diferentes sistemas (Institutos Federais, CEFETs ${ }^{5}$, Secretarias Estaduais de Educação, etc.), caracterizando-se como uma das principais formas atuais de acesso ao ensino médio profissionalizante no Brasil, e visa integrar o ensino médio com o ensino técnico, mas ainda carece de melhores esclarecimentos acerca de seus pressupostos epistemológicos, filosóficos e pedagógicos, que podem influenciar a prática docente.

O EMI tem origem ideológica e filosófica em premissas marxistas, especialmente na concepção de trabalho como princípio educativo geral e como ferramenta para a transformação e conscientização da sociedade, também chamada de formação humana omnilateral (Manacorda, 1991). Embora defendida pela maioria dos educadores e dos pesquisadores que tomaram parte nas discussões acerca da revogação do Decreto $n^{\circ}$ 2.208/97 e na gênese e promulgação do Decreto $n^{0}$ 5.154/04 (que instituiu as novas políticas públicas acerca do ensino médio profissionalizante), tal formação não foi totalmente contemplada no texto do novo decreto, nem mesmo em documentos oficiais posteriores que buscaram esclarecer e nortear os rumos da chamada Educação Profissional Técnica de Nível Médio (EPTNM). Sendo assim, muitos pesquisadores se dedicaram ao tema nos últimos anos, na intencionalidade de mostrar concepções e contradições do EMI, à luz dos pressupostos filosóficos e ideológicos aos quais se alinham, mirando um diálogo com os aspectos pedagógicos e práticos.

Diante dessas perspectivas, queremos entender o papel do professor que atua no EMI e buscamos pensar acerca de como esse ator se coloca e desenvolve a sua prática em sala de aula, em meio à falta de clareza que decorre, por um lado, das lacunas deixadas pelos documentos oficiais e, por outro lado, do aparente distanciamento entre os objetivos demarcados ideologicamente nos vários artigos sobre EMI e a realidade do mundo globalizado do século XXI.

Para captar e compreender esta perspectiva, entrevistamos, no formato semiestruturado, três professores de matemática que atuam no EMI, em escolas estaduais de educação profissional (EEEP) no interior do Ceará, buscando ouvi-los para entender qual a sua visão, a sua concepção de sua prática docente e também conhecer a sua formação profissional.

Embora a maioria dos resultados e das discussões oriundos desses levantamentos possa ser objeto de análise e reflexão também para outras disciplinas, o nosso foco é a

${ }^{5}$ CEFET é a sigla de Centro Federal de Educação Tecnológica. 
matemática, justificado pela experiência do primeiro autor como professor desta disciplina no EMI, além do fato de que este artigo é um recorte de sua pesquisa de doutorado, na linha de Ensino de Matemática, no PEMAT/UFRJ, orientada pela segunda autora. Os resultados e as conclusões, embora restritos aos sujeitos e à realidade institucional, cultural e social na qual estão inseridos, podem (e devem) suscitar reflexões acerca de como o EMI vem sendo concebido e trabalhado em todo o País, especialmente na visão de nossos professores, a fim de conhecer, avaliar e, se preciso for, rediscutir e (re)dimensionar esta modalidade e a formação profissional do seu corpo docente.

\section{O EMI nos Documentos Oficiais}

O atual modelo de Ensino Médio Integrado foi criado através do Decreto no 5.154/04, construído após a revogação do Decreto $n^{\circ}$ 2.208/97, com a missão de inserir uma nova concepção de ensino médio e educação profissional, que superasse o antagonismo entre o trabalho intelectual e o trabalho manual, com um ensino pautado na realidade brasileira.

No caso da formação integrada ou do ensino médio integrado ao ensino técnico, o que se quer com a concepção de educação integrada é que a educação geral se torne parte inseparável da educação profissional em todos os campos onde se dá a preparação para o trabalho: seja nos processos produtivos, seja nos processos educativos como a formação inicial, como o ensino técnico, tecnológico ou superior. (SETEC, 2007, p. 41)

O EMI é oferecido em forma de matrícula única para cada aluno, garantindo assim a formação geral do ensino médio e a formação profissional técnica (Gonçalves, 2012). Existe ainda outra modalidade de ensino médio profissionalizante chamada concomitante, oferecida a quem está ingressando no ensino médio, ou já o esteja cursando, efetuando-se matrículas distintas para cada curso e podendo ocorrer em diferentes instituições de ensino ou em uma única. Há ainda a modalidade subsequente, voltada exclusivamente à formação técnica e destinada somente a quem já concluiu o ensino médio.

A articulação entre a educação profissional técnica de nível médio e o ensino médio dar-se-á de forma:

I - integrada, oferecida somente a quem já tenha concluído o ensino fundamental, sendo o curso planejado de modo a conduzir o aluno à habilitação profissional técnica de nível médio, na mesma instituição de ensino, contando com matrícula única para cada aluno;

II - concomitante, oferecida somente a quem já tenha concluído o ensino fundamental ou esteja cursando o ensino médio, na qual a complementaridade entre a educação profissional técnica de nível médio e o ensino médio pressupõe a existência de matrículas distintas para cada curso, podendo ocorrer:

a) na mesma instituição de ensino, aproveitando-se as oportunidades educacionais disponíveis;

b) em instituições de ensino distintas, aproveitando-se as oportunidades educacionais disponíveis; ou

c) em instituições de ensino distintas, mediante convênios de intercomplementaridade, visando o planejamento e o desenvolvimento de projetos pedagógicos unificados; III - subsequente, oferecida somente a quem já tenha concluído o ensino médio. 
(Decreto $\mathrm{n}^{\circ} 5.154,2004$, p. 2)

Como podemos ver, o Decreto $n^{\circ} 5.154 / 04$ não contemplou somente o EMI. Ele indicou cinco possibilidades de se obter formação técnica de nível médio: integrado, concomitantes (a), (b) e (c), e subsequente.

Gonçalves (2012) ainda explicita que a EPTNM tem suas diretrizes nacionais aprovadas pela Resolução CNE/CEB nº 02/1997 e pelas alterações feitas pelas Resoluções CNE/CEB $n^{\circ} 01 / 2005, n^{\circ} 04 / 2005$ e $n^{\circ} 06 / 2012^{6}$. A EPTNM oferecida na modalidade integrada deve possuir projetos pedagógicos unificados, direcionando a pretensão de um diálogo constante entre os conteúdos e entre as disciplinas propedêuticas (núcleo comum) e as disciplinas técnicas (específicas). Identidade, Diversidade e Autonomia; Contextualização; e Interdisciplinaridade fazem parte das Diretrizes Curriculares Nacionais para o EMI.

Pressupostos oficiais sobre o Integrado podem ser observados em um documento do MEC, intitulado: Educação Profissional Técnica de Nível Médio Integrada ao Ensino Médio (SETEC, 2007). De acordo com Batista (2012), o documento visa nortear a articulação das categorias Trabalho, Cultura, Ciência e Tecnologia, com o intuito de possibilitar aos jovens a sistematização do conhecimento construído pelo homem ao longo de sua história. Neste documento (SETEC, 2007), no que tange à formação dos professores que atuam nos cursos integrados, podemos destacar:

Os professores das disciplinas específicas são formados, em geral, em bacharelados, não possuindo a formação desejada para o exercício da docência. $\mathrm{O}$ parecer do $\mathrm{CNE} / \mathrm{CEB} \mathrm{n}^{\circ}$ 02/97 dispõe sobre os programas especiais de formação pedagógica de professores para a Educação Profissional, mas os mesmos precisam ser revistos, pois não atendem a necessidade de formação, principalmente dos sistemas estaduais de ensino. Também é necessário levar em consideração que mesmo os professores licenciados carecem de formação com vistas à atuação no Ensino Médio Integrado, posto que tiveram sua formação voltada para a atuação no ensino fundamental e no Ensino Médio de caráter propedêutico, uma vez que as licenciaturas brasileiras, em geral, não contemplam em seus currículos estudos sobre as relações entre trabalho e educação ou, mais especificamente, sobre a educação profissional e suas relações com a educação básica. (p. 33)

A formação, tanto do professor das disciplinas específicas quanto daquele que atua nas disciplinas propedêuticas, precisa receber o devido direcionamento para a atuação no Ensino Médio Integrado. Essa formação docente, dentre outros aspectos, deve contemplar três eixos fundamentais: a articulação da educação profissional e técnica com a educação básica, a junção da formação didática com a formação política e pedagógica e os conhecimentos específicos de determinada área profissional. Ainda em SETEC (2007), vemos que a formação dos profissionais para o ensino médio integrado deve guardar suas especificidades, mas também precisa estar inserida em um campo mais amplo, o da formação de profissionais para a Educação Profissional e Tecnológica (EPT).

\footnotetext{
${ }^{6}$ Documentos disponíveis no site da Secretaria de Educação Profissional e Tecnológica do Ministério da Educação <http://portal.mec.gov.br/index.php?option=com_content\&view=article\&id=12683\%3Atecnico-denivel-medio\&catid=190\%3Asetec $\&$ Itemid=861>
} 
Visando superar essa falta de formação de profissionais para a EPT, surgiram, nos últimos anos, algumas especializações ${ }^{7}$, voltadas mais para quem não tem licenciatura, o que se restringe praticamente aos professores da base técnica. E, no ano de 2016, foi criado o ProfEPT (Mestrado Profissional em Educação Profissional e Tecnológica em Rede Nacional), semipresencial, sob responsabilidade do Instituto Federal de Educação, Ciência e Tecnologia do Espírito Santo (IFES), chancelado pela Coordenação de Aperfeiçoamento de Pessoal de Nível Superior (CAPES), pela Resolução CS no 161/2016. Em nosso entendimento, trata-se de uma iniciativa louvável, que prevê em seu ementário de disciplinas alguns importantes textos de referência sobre Educação e Trabalho e sobre Educação Profissional. A primeira turma do ProfEPT teve início no segundo semestre de 2017, com 18 polos espalhados por todo o território nacional.

Existe, ainda, uma evidente falta de clareza nos documentos oficiais acerca de como o EMI pode contemplar, de modo eficaz, tanto o ensino técnico quanto o ensino propedêutico.

Na hipótese prevista no inciso I (Ensino Integrado) do $\S 1^{\circ}$, a instituição de ensino deverá, observados o inciso I do art. 24 da Lei $\mathrm{n}^{\circ}$ 9.394, de 1996, e as diretrizes curriculares nacionais para a educação profissional técnica de nível médio, ampliar a carga horária total do curso, a fim de assegurar, simultaneamente, o cumprimento das finalidades estabelecidas para a formação geral e as condições de preparação para o exercício de profissões técnicas. (Decreto n ${ }^{\circ} 5.154,2004$, p. 3)

Faz-se menção apenas à ampliação da carga horária (aspecto quantitativo), mas nada se manifesta acerca de como a articulação entre a formação humana e cultural, a formação propedêutica e a formação técnica específica deve acontecer, para garantir essa dupla função do Ensino Integrado (aspecto qualitativo), haja vista que a formação geral, que dará possibilidade de acesso à universidade, não pode ser desprestigiada. $\mathrm{O}$ currículo do ensino médio (seja ele regular, concomitante ou integrado), de acordo com a Lei de Diretrizes e Bases da Educação (LDB) 9.394/96, Seção IV, tem como finalidades:

I - a consolidação e o aprofundamento dos conhecimentos adquiridos no ensino fundamental, possibilitando o prosseguimento de estudos;

II - a preparação básica para o trabalho e a cidadania do educando, para continuar aprendendo, de modo a ser capaz de se adaptar com flexibilidade a novas condições de ocupação ou aperfeiçoamento posteriores;

III - o aprimoramento do educando como pessoa humana, incluindo a formação ética e o desenvolvimento da autonomia intelectual e do pensamento crítico;

IV - a compreensão dos fundamentos científico-tecnológicos dos processos produtivos, relacionando a teoria com a prática, no ensino de cada disciplina.

(p. 12)

Vê-se que o discurso oficial, constante em documentos, leis e decretos do MEC, não é objetivamente claro em muitos aspectos acerca do EMI. Muitas questões podem ser levantadas, mas nem todas respondidas sem um profundo debate, minuciosas pesquisas e muitas reflexões. Qual o papel do professor nessa articulação entre o ensino profissional e o ensino propedêutico? Nossos professores estão sendo devidamente formados e/ou preparados

\footnotetext{
${ }^{7}$ Pós-graduação em nível lato sensu.
} 
para atuar no EMI? Quais os pressupostos ideológicos, políticos, filosóficos, que subjazem à conceitualização do EMI? Alguns destes questionamentos podem ser mais bem compreendidos, ouvindo alguns atores deste processo: educadores que participaram da gênese do Decreto 5.154/04, pesquisadores que têm se debruçado sobre o assunto e professores que estão neste momento em sala de aula em turmas de EMI. Esta investigação visa contribuir para a reflexão sobre a concepção do professor de matemática acerca do Ensino Médio Integrado e os desdobramentos com vistas à formação docente para atuar nesta modalidade.

\section{O que Pensam os Pesquisadores e Educadores Sobre o Tema}

Ao longo dos últimos 12 anos, ou seja, desde a revogação do Decreto n ${ }^{\circ}$ 2.208/97 e a aprovação do Decreto $\mathrm{n}^{\circ}$ 5.154/04, o número de textos e artigos constantes em periódicos, capítulos de livros e anais de eventos que discutem o Ensino Médio Integrado em todo o País tem sido bastante considerável. O debate que culminou no novo decreto é antigo, mas se (re)intensificou a partir de 2003, com o início do governo do Partido dos Trabalhadores. Para alguns pesquisadores e educadores, isso representou, finalmente, ver um avanço significativo, em termos práticos, das ideias que há décadas vinham sendo debatidas e adaptadas à realidade brasileira.

Na obra organizada por Frigotto, Ciavatta e Ramos (2005), intitulada Ensino Médio Integrado: concepção e contradições, temos a oportunidade de fazer uma verdadeira imersão nos bastidores dos embates que culminaram na aprovação do Decreto $n^{\circ}$ 5.154/04 e temos acesso a debates e pesquisas anteriores e contemporâneas a essa aprovação. Estes mesmos pesquisadores também deram importantes contribuições a essa temática em pesquisas mais recentes. Em um dos artigos da obra, Ramos (2005) destaca que EMI não é apenas a sobreposição de disciplinas técnicas com disciplinas propedêuticas:

É importante reiterar que a sobreposição de disciplinas consideradas de formação geral e de formação específica ao longo de um curso não é o mesmo que integração, assim como não o é a adição de um ano de estudos profissionais a três de ensino médio (a chamada estrutura 3+1). A integração exige que a relação entre conhecimentos gerais e específicos seja construída continuamente ao longo da formação, sob os eixos do trabalho, da ciência e da cultura. (p. 122).

Neste paradigma de se pensar uma formação construída sob os eixos do trabalho, da ciência e da cultura, Ramos (2008) defende que o EMI precisa ir de encontro à ideia de escola unitária:

Os antecedentes histórico-políticos da concepção de ensino médio integrado à educação profissional demonstram o caráter ético-político do tema, posto que esse debate coincide com debates sobre projetos de sociedade e concepções de mundo....defendemos naquele período o projeto de escola unitária, que visa superar a dualidade da formação para o trabalho manual e para o trabalho intelectual. (p. 2)

O conceito de Escola Unitária nos remete ao filósofo marxista italiano Antonio Gramsci. Para Gramsci (1991), a escola unitária seria uma escola "desinteressada", do ensino 
intelectual e do trabalho para todos. O termo "interessado/desinteressado", de acordo com Nosella e Azevedo (2013), não se refere a algum descomprometimento político e ideológico. Gramsci (1991) entendia, e defendia, que a escola (unitária) deveria promover a inserção da juventude na atividade social, após levar o jovem a certo grau de maturidade, à criação intelectual e prática e a certa autonomia na orientação e na iniciativa.

Além da ideia de escola unitária, o EMI é alinhado a outro paradigma filosófico e ideológico, que é a Formação Politécnica. Para alguns autores, o Ensino Integrado seria uma travessia entre o modelo tradicional de Educação e a formação politécnica. No final da década de 1980, um intenso debate envolvendo entidades educacionais e científicas mobilizou a incorporação do direito à educação pública, laica, democrática e gratuita na Constituição (Frigotto et al., 2005). No que concerne à educação básica, caminhava-se na perspectiva marxista de trabalho como princípio educativo. Os autores relatam que, nessa perspectiva, não se deveria propor a formação de técnicos especializados, mas sim de politécnicos.

o ideário da politecnia buscava e busca romper com a dicotomia entre educação básica e técnica, resgatando o princípio da formação humana em sua totalidade; em termos epistemológicos e pedagógicos, esse ideário defendia um ensino que integrasse ciência e cultura, humanismo e tecnologia, visando ao desenvolvimento de todas as potencialidades humanas. Por essa perspectiva, o objetivo profissionalizante não teria fim em si mesmo nem se pautaria pelos interesses do mercado, mas constituir-se-ia numa possibilidade a mais para os estudantes na construção de seus projetos de vida, socialmente determinados, possibilitados por uma formação ampla e integral. (Frigotto et al., 2005, p. 35)

Nesse sentido, o termo "politecnia" coaduna harmoniosamente com a formação omnilateral, que, de acordo com Manacorda (1991), significa justamente a premissa marxista de que o homem deve se sentir completo a partir de sua convivência em sociedade e de seu trabalho (formação humana em sua totalidade).

Estes autores reforçam que tudo o que foi debatido e construído nos anos 1980, buscou-se resgatar nos debates que se seguiram imediatamente após a revogação do Decreto $\mathrm{n}^{\mathrm{o}}$ 2.208/97. Eles apontam que, mesmo em meio a contradições, o Decreto $\mathrm{n}^{\mathrm{o}}$ 5.154/04 chancelou a consolidação da base unitária do ensino médio, respeitando a diversidade inerente à realidade brasileira, e, assim, possibilitando a ampliação dos objetivos de vida dos alunos, seja para atuar profissionalmente na área técnica de sua escolha ou prosseguir rumo à universidade ou, até mesmo, trabalhar e estudar na universidade. Neste ponto, entendemos que o EMI não contempla fielmente a formação politécnica, mas se apropria de alguns de seus valores, contribuindo (possivelmente) para vencer a dualidade na educação brasileira: formação geral e intelectual para as elites e educação para o trabalho manual para as classes menos abastadas.

Para Ciavatta (2005), o termo "Integrado" remete ao sentido de completude, de compreensão das partes de um todo social, nas múltiplas mediações históricas que concretizam os processos educativos. Citando Gramsci, a autora associa ao EMI a noção de 
indistinguibilidade entre educação geral e educação profissional. Ela apresenta sete pressupostos para a realização plena do EMI: (a) existência de um projeto de sociedade que vise superar o dualismo de classes e atuação de agentes da educação engajados politicamente, (b) manutenção do foco no rompimento do dualismo, através da articulação (prevista em lei) entre a formação geral e a formação profissional, (c) adesão de gestores e professores, (d) articulação da instituição com alunos e familiares, (e) compreensão do EMI como uma experiência de democracia participativa, (f) resgate da escola como um lugar de memória e (g) garantia de investimentos públicos na educação. Tudo isso implica investimentos vários: intelectuais, morais e financeiros. A aprovação do Decreto $\mathrm{n}^{\circ}$ 5.154/04 não garante a implementação do EMI. Isso depende nevralgicamente do interesse e da compreensão de EMI de políticos, gestores, professores, escolas, sistemas escolares, alunos (com suas famílias).

Ramos (2005) fala acerca de possibilidades e desafios na organização do currículo integrado. O texto discute a organização deste currículo sob os seguintes quatro movimentos:

[1] Problematizar fenômenos - fatos e situações significativas e relevantes para compreendermos o mundo em que vivemos, bem como processos tecnológicos da área profissional para a qual se pretende formar -, como objetos de conhecimento, buscando compreendê-los em múltiplas perspectivas: tecnológica, econômica, histórica, ambiental, social, cultural, etc.... [2] Explicitar teorias e conceitos fundamentais para a compreensão do(s) objeto(s) estudado(s) nas múltiplas perspectivas em que foi problematizada e localizá-los nos respectivos campos da ciência (áreas do conhecimento, disciplinas científicas e/ou profissionais), identificando suas relações com outros conceitos do mesmo campo (disciplinaridade) e de campos distintos do saber (interdisciplinaridade).... [3] Situar os conceitos como conhecimentos de formação geral e específica, tendo como referência a base científica dos conceitos sua apropriação tecnológica, social e cultural... [4] A partir dessa localização e das múltiplas relações, organizar os componentes curriculares e as práticas pedagógicas, visando a corresponder, nas escolhas, nas relações e nas realizações, ao pressuposto da totalidade do real como síntese de múltiplas determinações. (Ramos, 2005, p. 123)

Como podemos notar, Ramos (2005) buscou levantar elementos e estabelecer conexões dos pressupostos filosóficos, ideológicos e epistemológicos com aspectos práticos do ensino, apontando um norte para a pedagogia do EMI. De fato, nada mais basilar, na construção de uma proposta pedagógica que dialogue com pressupostos bem delineados, do que se pensar o currículo.

Acerca da formação dos professores do EMI, há poucas pesquisas e estudos. Machado (2008) trata da formação dos professores para atuar na EPT, em que se inclui o EMI. O debate ficou restrito aos docentes das disciplinas técnicas, enquanto nosso principal interesse reside na formação dos professores de matemática, se estendendo às demais disciplinas propedêuticas. Para os docentes das disciplinas técnicas, Machado (2008) defende que haja licenciaturas (formação inicial) que contemplem os eixos e os valores necessários para atuar na EPT. No entanto, o professor das disciplinas propedêuticas (matemática, física, história, etc.) já tem sua formação em nível de licenciatura, mas, como citado antes (SETEC, 2007), 
ela não é suficiente para prepará-lo para a docência no ensino integrado. Ainda assim, Machado (2008) faz questão de deixar claro que, neste contexto, "professores de educação básica e de educação profissional comungam das mesmas necessidades com relação à valorização de sua formação" (p. 8).

O EMI, na concepção daqueles que participaram de sua gênese e construção, é pautado em pressupostos filosóficos e ideológicos, e comprometido com uma determinada agenda política. Interessa-nos compreender como esta perspectiva se materializa (ou não) nos aspectos práticos, da sala de aula. Para isso, buscamos entender o papel e a visão do professor nesse processo.

\section{A Experiência Docente no Ensino Médio Integrado}

Apresentamos, a seguir, a síntese do que pensam os docentes do EMI. Para captar uma compreensão do que encontramos nos documentos oficiais e na literatura sobre o tema, sob o prisma de suas concepções, entrevistamos três professores de matemática de EEEPs situadas no interior do Ceará. Utilizamos o formato semiestruturado, e a nossa ideia foi conversar com esses profissionais e tentar compreender possíveis convergências e divergências entre o EMI teorizado e o EMI que acontece na sala de aula. Os sujeitos da pesquisa assinaram um termo de consentimento livre e esclarecido, autorizando as entrevistas, e foram resguardados seus direitos a pleno anonimato. Para reforçar essa premissa ética, não utilizaremos nomes, nem mesmo fictícios. Os três docentes serão referidos como PEMI-01, PEMI-02 e PEMI-03 ${ }^{8}$.

Centramos nossas entrevistas em dois eixos, a seguir destacados, objetivando conhecer aspectos da prática (intencionada) e da formação do profissional. Nesse sentido, analisamos a visão que os docentes têm a respeito das questões propostas. De forma mais específica, nos focamos em investigar, a partir das próprias concepções dos entrevistados: (1) Como o professor de matemática do EMI concebe esta modalidade e como essa sua concepção influencia (ou é influenciada por) sua prática docente; (2) Como ocorre ou deveria ocorrer a formação do professor de matemática do EMI.

\section{Analisando a Visão dos Professores - Eixo 1}

A visão dos três professores, sujeitos da pesquisa, acerca do EMI é o foco de nossa análise nesta subseção. Os docentes mostraram conhecer apenas superficialmente a ideia de ensino médio integrado que consta nos documentos oficiais, consensualmente definindo-o como sendo a junção ${ }^{9}$ do ensino técnico com o ensino propedêutico, mas confessam que atuam de modo muito semelhante à sua experiência anterior no ensino regular e que as especificidades que diferenciam esta prática estão muito mais ligadas a outros aspectos das EEEP, que fogem ao fato de trabalharem exclusivamente com o Ensino Integrado. Em alguns

\footnotetext{
${ }^{8}$ PEMI $=$ Professor do Ensino Médio Integrado.

${ }^{9}$ Usaram palavras diferentes que, na pormenorização dada por cada um, apontavam para a mesma perspectiva: (junção, mistura, articulação).
} 
momentos, todos mostraram uma ligeira confusão entre ensino integrado e ensino em tempo integral e, claramente, não conseguiram diferenciar a modalidade "concomitante" da modalidade "integrado". Nesse ponto, percebemos que desconheciam tanto os pressupostos filosóficos e políticos levantados pelos pesquisadores quanto os documentos oficiais do MEC.

A falta de clareza acerca de certas questões, por parte do próprio professor, que atua diariamente dentro da sala de aula e do ambiente escolar implica em um enfraquecimento de algumas ideias. Ciavatta (2005), como escrevemos na seção anterior, não concebe uma proposta de EMI que não contemple um envolvimento coeso dos agentes, especialmente a tríade sistema escolar, gestão escolar e professores. Para não fugir do nosso foco, não buscamos investigar diretamente a postura e os objetivos da gestão da escola ou do sistema escolar em questão, mas os depoimentos dos próprios professores mostram que este envolvimento não é coeso.

Não há uma política (nem dentro da escola, nem do sistema escolar) que convirja, por exemplo, para uma legítima integração entre as disciplinas técnicas e as disciplinas propedêuticas. As primeiras são ministradas por um corpo docente da base técnica e as propedêuticas por um outro corpo docente, da base comum. Até mesmo as carreiras são diferenciadas, havendo, inclusive, diferenças salariais e contratuais. Os docentes da base técnica são celetistas, vinculados ao $\operatorname{CENTEC}^{10}$ e os professores da base comum são servidores públicos estaduais vinculados à Secretaria da Educação do Ceará (SEDUC). Somente professores contratados para atuar na base técnica podem ministrar disciplinas técnicas e somente os professores da base comum podem ministrar disciplinas propedêuticas.

Os professores entrevistados também falaram sobre a dificuldade de diálogo e articulação entre a matemática que ensinam e as disciplinas técnicas, especialmente as disciplinas afins. A disciplina Cálculo Diferencial, por exemplo, é ministrada por um professor da base técnica que não possui formação matemática. O professor PEMI-03, ao relatar um caso em que um dos professores de uma disciplina técnica ensinava erradamente a resolver um sistema de duas equações do primeiro grau a duas incógnitas, apontou uma deficiência nitidamente conceitual. O docente PEMI-02, por sua vez, se mostrou receoso em tentar direcionar um diálogo com as disciplinas técnicas, algo previsto nos documentos oficiais e visto com bons olhos pelos educadores ligados ao EMI, e revelou que já buscou realizar isso anteriormente, mas sem sucesso, pois havia divergências entre o que a proposta curricular previa e o que o professor da base técnica, de fato, trabalhava em sala de aula. Neste aspecto, percebemos uma convergência para algo que Ramos (2005) denuncia como não sendo ensino integrado, pois há apenas uma sobreposição de disciplinas técnicas e propedêuticas, desarticuladas.

\footnotetext{
${ }^{10}$ O Instituto Centro de Ensino Tecnológico - CENTEC - foi criado em 1999, é uma sociedade civil de direito privado, sem fins lucrativos, e tem a missão de promover a educação e as atividades tecnológicas necessárias ao desenvolvimento dos municípios, por meio do ensino, da pesquisa e da extensão, em áreas estratégicas para a inclusão social e a inovação no Estado do Ceará.
} 
Tanto PEMI-02 quanto PEMI-03 se mostraram céticos em relação a alguns aspectos da proposta do EMI, ao ofertar uma articulação dialógica entre ensino técnico e ensino propedêutico, especialmente por perceberem que a grande maioria dos alunos só está interessada, de fato, na formação propedêutica, com vistas à habilitação e à preparação para prosseguimento de estudos (ENEM e vestibulares), e são raros os casos em que os egressos realmente usam seu diploma de técnico para atuar na área profissional para a qual foram preparados.

[o aluno] já vem pensando em cursar uma faculdade e sabe que nunca vai usar o curso técnico, mas faz porque é obrigado mesmo, então eu acho que essa obrigatoriedade de ter que cursar os dois... num é tão legal não. Não que não tivesse a base técnica, mas que o aluno pudesse optar. (PEMI-03)

Neste ponto, entendemos que alguns dos pressupostos elencados por Ciavatta (2005) não somente são indispensáveis para se ter um ensino efetivamente integrado, como se vê que eles não estão sendo levados em conta, pois os próprios alunos, possivelmente apoiados pelos pais, têm recorrentemente valorizado mais o ensino propedêutico do que o técnico.

De todos os entrevistados, PEMI-01 é o professor que, nitidamente, mais simpatiza com a proposta do EMI. Embora também sinta algumas dificuldades em estabelecer um diálogo de suas aulas de matemática com as disciplinas técnicas e também tenha críticas acerca das diferenciações e do distanciamento entre os docentes das duas bases, ele afirma que sempre planeja suas aulas sistematicamente de acordo com o curso em que irá trabalhar determinada lição ou conteúdo.

os exercícios e exemplos, eu tento buscar aplicado e relacionado ao curso. Por exemplo, estou explicando sistema linear ... no curso de administração, eu tento buscar algo que tenha relação com o curso que eles vão administrar, não sei. Dependendo. Já em eletrotécnica, busco exercícios que envolvam um pouco de eletricidade, já que tem a ver com o curso. Eu tento buscar exercícios e analogias que sejam um pouco mais interessantes. (PEMI-01)

Esta postura converge para alguns dos pressupostos de Ramos (2005) para estruturação e elaboração do currículo integrado. Esta autora defende, entre outras coisas, que o currículo deve ser baseado numa pedagogia que articule dialogicamente os conhecimentos gerais e específicos, o que aparentemente ocorre na prática de PEMI-01.

\section{Analisando a Visão dos Professores - Eixo 2}

A formação dos três professores entrevistados, no que se refere ao direcionamento para atuação no EMI, é praticamente inexistente. Importa destacar que nos referimos aqui à formação docente institucionalizada, seja em sua instância inicial (licenciatura em matemática), seja na instância continuada, feita pelos docentes e/ou ofertada pela escola ou pelo sistema de ensino, e deixamos isso muito claro durante as entrevistas. Eles nunca tiveram nenhum tipo de preparação, ou mesmo explicação, sobre os pressupostos filosóficos e políticos do EMI, sua missão social, sua história, etc. Não foram convidados a refletir sobre as especificidades dos aspectos pedagógicos e curriculares do EMI. Eles relatam que 
aprenderam o que sabem sobre o EMI dentro da própria prática, através da experiência e do diálogo com os demais colegas profissionais da própria escola. "Formação voltada para o ensino integrado mesmo a gente nunca teve... eu, assim, pelo menos, não participei. Não participei, participei de outras mais voltadas, por exemplo, pro laboratório... para laboratórios, práticas de laboratórios, teve uma voltada para informática" (PEMI-02).

Todos são concordantes acerca da necessidade de uma formação docente voltada para atuar no EMI, mas acreditam que deve ocorrer dentro da formação continuada, e não na formação inicial, pois, de acordo com PEMI-03, por exemplo, quando está na licenciatura, o futuro professor de matemática, normalmente, ainda não sabe se atuará ou não no ensino médio integrado.

Eu acho complicado [na formação inicial], porque, quando você faz a faculdade, você não sabe em qual você vai trabalhar.... eu acredito que a própria universidade deveria preparar para o cara dar aula mesmo, a realidade da sala de aula, porque às vezes a gente sai da faculdade achando que vai transformar o mundo, que vai mudar tudo e quando chega lá na sala de aula é outra realidade. Mas sobre a parte profissional, eu acho que mais na formação continuada, porque quando você vai entrar [em sala de aula no EMI] não tem, não tem ninguém que diz como é que vai ser ou o que é que tem que fazer. Você vai aprender no dia a dia, eu mesmo comecei a aprender muita coisa aqui. Eu fui aprendendo no dia a dia, com a ajuda do coordenador da minha área. (PEMI-03)

Essa percepção dos professores contradiz Machado (2008), que prefere licenciaturas (formação inicial) que contemplem os eixos e os valores necessários para atuar na EPT, como formação indispensável para os professores. Entendemos que também se faz necessário pensar acerca de um espaço e um investimento coletivo do ensino, como eixos de interlocução entre todos os professores.

O discurso comum a todos é de que aprenderam a trabalhar no EMI no dia a dia, mas o ideal é que o professor tenha algum tipo de curso de formação, já depois de sua formação inicial (licenciatura), direcionado para atuar nesta modalidade, e que, continuamente, novos momentos de formação possam ocorrer para aperfeiçoar e alinhar a sua prática docente com o que se propõe teoricamente.

\section{A Perspectiva Captada}

Nossa percepção, em linhas gerais, a partir dos estudos teóricos e analisando as entrevistas, é de que as concepções e as preocupações dos professores parecem destoar parcialmente dos pressupostos filosóficos e ideológicos que subjazem ao Ensino Médio Integrado. Não conseguimos captar se tal desajuste é motivado por uma legislação que, possivelmente, foi concebida de modo a não favorecer a integração. Enquanto esses pressupostos preconizam uma visão ideologizada de trabalho como princípio educativo geral (Frigotto et al., 2005; Manacorda, 1991; Ramos, 2005), os professores estão, pragmaticamente, mais preocupados em dar boas aulas de sua disciplina, embora reconheçam a difícil missão de preparar seus alunos para saírem da instituição com uma boa formação técnica e também para ingressar no ensino universitário. Um dos entrevistados (PEMI-03), 
por exemplo, entende que valorizar a autonomia de decisão do aluno entre fazer apenas o ensino médio (propedêutico) ou ambos é mais importante do que dar apenas a opção de fazer o ensino médio integrado. No entanto, Frigotto et al. (2005) acreditam que o EMI deveria ser aberto a todos os estudantes brasileiros ingressantes no Ensino Médio e criticam indiretamente as outras possibilidades de ingresso na EPTNM.

Em alguns poucos aspectos, o discurso dos professores parece convergir com a proposta do MEC, como a tentativa de promover a formação profissional técnica, sem desprestigiar a preparação para prosseguir os estudos. No entanto, é preocupante o descompasso, unanimemente relatado, entre a base técnica e a base comum. O que percebemos, ao invés de um ensino integrado, é uma verdadeira desintegração, em que a falta de diálogo é um aspecto evidente. O fato de serem carreiras diferenciadas já gera, possivelmente, uma estranheza e um afastamento. Pressupomos que esta realidade não ocorre, por exemplo, nos Institutos Federais, onde os professores têm carreira única ${ }^{11}$, independentemente de lecionar disciplinas técnicas ou propedêuticas, sendo que, muitas vezes, há profissionais que atuam nas duas bases.

Os professores - até mesmo os que não são simpáticos com a proposta integradora demonstram certa preocupação para que a dupla missão de preparar para o mundo do trabalho e também para o ingresso na universidade seja exitosa. Todos se mostraram dispostos a buscar a integração, mas também apresentaram as dificuldades que se mostram como obstáculos para qualquer iniciativa: a falta de colaboração por parte de colegas da base técnica; a ausência de apoio dos coordenadores escolar e de cursos; a própria estrutura institucional, que não converge plenamente para esta proposta; e a falta de uma formação docente que os equipe com os saberes necessários para atuar no EMI.

A ausência total de um programa de formação docente voltado para quem vai atuar no EMI é um traço marcante para corroborar essa falta de apoio institucional e político. Pensar (e olhar para) a formação do professor, não somente de matemática, mas de todas as disciplinas do EMI, é uma urgência gritante. Este desamparo denuncia flagrantemente o descumprimento do que consta no documento (SETEC, 2007) que aponta que tanto a formação dos professores da base técnica quanto a dos que atuam na base comum, necessitam de um olhar especial e direcionado.

\section{Articulando as Três Perspectivas}

De posse dessas informações e de diferentes perspectivas, afinal de contas, seria interessante buscar responder: "o que é o ensino médio integrado"? Há uma resposta fechada que contemple todos os pressupostos (teóricos, filosóficos, políticos, práticos)?

\footnotetext{
11 Os docentes dos Institutos Federais possuem carreira EBTT (Magistério do Ensino Básico, Técnico e Tecnológico).
} 
Indubitavelmente, vê-se que o EMI é multifacetado, plural e complexo. As convergências e divergências, nesta perene triangulação (entre documentos oficiais; pesquisadores e educadores; professores do EMI), nos fazem perceber que mais importante do que obter uma resposta fechada para a pergunta acima é levantar elementos suficientes para o aprofundamento no debate sobre este assunto e fomentar reflexões que possam contribuir para pesquisas futuras. Sem incorrer no risco de ser simplistas, percebemos que, de certa forma, podemos pensar nas três perspectivas da seguinte maneira:

(i) Os documentos oficiais do MEC demonstram uma preocupação política mais inclusiva em sua oferta de EPTNM, na qual consta o EMI, independentemente de suas motivações. Essa preocupação se torna aparente no momento em que o debate que gerou o Decreto $n^{\circ} 5.154 / 04$ resulta não apenas na formação integrada, defendida pela ala mais progressista, mas também no indispensável subsequente (para os que já concluíram o ensino médio regular) e o concomitante (em suas três versões possíveis) (Brasil, 2004; SETEC, 2007). A falta de clareza desses documentos, ao definir como o EMI deve acontecer dentro da sala de aula e qual o papel de cada professor nesta proposta, pode estar gerando desencontros na prática profissional dos docentes.

(ii) Por outro lado, os principais educadores brasileiros que pesquisam sobre Educação e Trabalho (Ciavata, 2008; Frigotto et al., 2005; Ramos, 2005) estão focados em fazer avançar uma determinada agenda política alinhada com os pressupostos de formação omnilateral (Manacorda, 1991) e de politecnia, de modo que o EMI serviria como uma ponte para esses modelos ideais e, em alguma medida, utópicos (Saviani, 2003), mesmo sem haver uma real nitidez dos aspectos pedagógicos e didáticos implicados. Claramente, necessita-se de um contato direto entre esses pressupostos e o professor do EMI, para que haja uma negociação entre o que faz sentido para a sala de aula e o que, pelo menos por enquanto, precisa continuar apenas no campo das ideias.

(iii) Os professores, por sua vez, apesar de não haver uma formação docente adequada para atuar nesta modalidade, estão focados em sua atuação na sala de aula, com conhecimento muito superficial dos interesses e dos pressupostos aqui citados e, ainda assim, empenhados em conseguir contribuir significativamente para que seu aluno conclua o EMI com uma boa formação técnica e preparado para o prosseguimento dos estudos. No que concerne à realidade das EEEP cearenses, urge pensar na unificação das carreiras dos docentes do EMI, com equiparação salarial e contratual, e o fim de qualquer diferenciação, implícita ou explícita, entre os professores das disciplinas técnicas e os das disciplinas propedêuticas. Isso seria um bom start para uma integração plena do corpo docente.

Em suma, compreendemos que os professores incorporaram uma perspectiva própria de Ensino Médio Integrado, que, numa via de mão dupla, alimenta e retroalimenta sua própria atividade docente e que tem alguns pontos de convergência e outros de divergência com o EMI teorizado pelos documentos oficiais e com a literatura sobre o tema. Um diálogo que mire uma aproximação entre a teoria e a prática pode ser construído através da criação e da implementação de um legítimo e bem planejado programa de formação de professores em 
serviço, em que, de um lado, esses profissionais receberiam as instruções e as explicações relativas aos aspectos teóricos do EMI e, em contrapartida, através das discussões, contribuiriam, retornando às instituições suas próprias perspectivas e modos de conceber o EMI. E, desta maneira, se possa caminhar para uma proposta efetiva de ensino integrado.

\section{Considerações Finais}

Inspirado por lacunas e falta de clareza nos pressupostos que sustentam a ideia de ensino integrado, este artigo buscou apresentar, discutir e articular três perspectivas acerca do Ensino Médio Integrado (EMI): (i) dos documentos oficiais, (ii) de pesquisadores e educadores e (iii) de docentes que atuam nesta modalidade de ensino. Enxergamos o EMI como uma das principais formas de acesso à educação profissional em nosso país, adensando a necessidade de se investigar e refletir sobre ele, especialmente olhando para o papel do professor como um dos protagonistas neste processo.

Nosso intuito maior não é dar um diagnóstico global, mas sim, partindo da premissa de que situações particulares podem apoiar informações gerais, identificar e discutir convergências e divergências entre o EMI teorizado e o EMI que é concebido e praticado pelos professores de matemática, a fim de levantar ideias e reflexões que fomentem um debate rico e produtivo acerca do tema. Compreendemos que a visão dos professores sobre os pressupostos e as características do cotidiano escolar fornece informações e ideias que não podem jamais ser ignoradas.

Como forma de articular as três perspectivas discutidas neste texto e superar a evidente ausência de suporte formativo aos professores, sugerimos a criação e a implementação de um programa de formação de professores do EMI in-service, no qual, de um lado, os docentes teriam contato direto com os aspectos teóricos e, em contrapartida, contribuiriam, através de seus apontamentos em discussões, dando o feedback de sua prática, de sua visão e seu modo de conceber e trabalhar o EMI. Entendemos que, assim, podemos caminhar para um EMI que, efetivamente, emane de um diálogo entre teoria e prática.

\section{Referências}

Batista, U. A. D. (2012). O ensino médio integrado e a relação entre a proposta da SEED/PR $e$ a realidade escolar: avanços ou permanências? Dissertação de Mestrado em Educação, Programa de Pós-Graduação em Educação. Curitiba: Universidade Federal do Paraná.

Conselho Nacional de Educação (CNE). (1997). Resolução CEB/CNE n. 02/1997. Retirado em 29 de janeiro, 2017, de: http://portal.mec.gov.br/setec/arquivos/pdf/RCNE_CEB02_97.pdf.

Conselho Nacional de Educação (CNE). (2005). Resolução CEB/CNE n. 01/2005. Retirado em $30 \quad$ de janeiro, 2017, de: http://portal.mec.gov.br/setec/arquivos/pdf_legislacao/rede/legisla_rede_resol1.pdf. 
Conselho Nacional de Educação (CNE). (2005). Resolução CEB/CNE n. 04/2005. Retirado em 31 de janeiro, 2017, de: http://portal.mec.gov.br/cne/arquivos/pdf/rceb04_05.pdf.

Conselho Nacional de Educação (CNE). (2012). Resolução CEB/CNE n. 06/1997. Retirado em 31 de janeiro, 2017, de: http://portal.mec.gov.br/index.php?option=com_docman\&view=download\&alias=11663 -rceb006-12-pdf\&category_slug=setembro-2012-pdf\&Itemid=30192.

Decreto $n^{\circ}$ 5.154, de 23 de julho de 2004. (2004). Retirado em 27 de dezembro, 2016, de: http://www.planalto.gov.br/ccivil_03/_ato2004-2006/2004/decreto/d5154.htm.

Secretaria de Educação Profissional e Tecnológica (SETEC). (2007). Educação Profissional Técnica de Nível Médio Integrada Ao Ensino Médio: Documento Base. Retirado em 25 de janeiro, 2017, de: http://portal.mec.gov.br/setec/arquivos/pdf/documento_base.pdf.

Ciavatta, M. A. (2005). A formação integrada: a escola e o trabalho como lugares de memória e de identidade. In G. Frigotto, M. Ciavatta, \& M. Ramos (Orgs.), Ensino médio integrado: concepção e contradições (pp. 83-106). São Paulo: Cortez.

Frigotto, G., Ciavatta, M., \& Ramos, M. (2005). A gênese do Decreto n ${ }^{\circ}$ 5.154/2004: um debate no contexto controverso da democracia restrita. In G. Frigotto, G., M. Ciavatta, \& M. Ramos (Orgs.), Ensino médio integrado: concepção e contradições (pp. 21-56). São Paulo: Cortez.

Gonçalves, H. J. L. (2012). A educação profissional e o ensino de matemática: conjunturas para uma abordagem interdisciplinar. Tese de Doutorado em Educação Matemática, Pontifícia Universidade Católica de São Paulo, São Paulo.

Gramsci, A. (1991). Concepções dialéticas da história. Rio de Janeiro: Civilização Brasileira.

Lei $n^{\circ}$ 9.394, de 20 de dezembro de 1996. (1996). Estabelece as diretrizes e bases da educação nacional. p.1-27, 1996. Retirado em 30 de janeiro, 2017, de: http://www.planalto.gov.br/ccivil_03/leis/19394.htm.

Machado, L. R. S. (2008). Diferenciais inovadores na formação de professores para a educação profissional. Revista Brasileira da Educação Profissional e Tecnológica, 1(1), 8-22.

Manacorda, M. A. (1991). Marx e a Pedagogia moderna (Newton Ramos de Oliveira, trad.). São Paulo: Cortez.

Ramos, M. (2005). Possibilidades e desafios na organização do currículo integrado. In G. Frigotto, M. Ciavatta, \& M. Ramos (Orgs.), Ensino médio integrado: concepção $e$ contradições (pp. 106-127). São Paulo: Cortez.

Ramos, M. (2008). Concepção do Ensino Médio Integrado. Texto apresentado em seminário promovido pela Secretaria de Educação do Estado do Pará nos dias 8 e 9 de maio de 2008. Retirado em 20 de novembro de 2016, de http://forumeja.org.br/go/sites/forumeja.org.br.go/files/concepcao_do_ensino_medio_int egrado5.pdf.

Saviani, D. (2003). O choque teórico da politecnia. Trabalho, Educação e Saúde, 1(1), 131152. 